\title{
CNS LUPUS PRESENTING AS ENCEPHALITIS : A CASE REPORT
}

\author{
AZAD KAK ${ }^{1}$, SARDAR MH ${ }^{2}$, APPOLO AM ${ }^{3}$, MALLIK MU ${ }^{4}$, SARKER M ${ }^{5}$

\begin{abstract}
:
An 18 years old female presented with several episodes of convulsions followed by unconsciousness. On admission, her Glasgow Coma Scale was 3, and other neurological and systemic examination revealed no abnormality. Initially it appeared to be a case of viral encephalitis with a background probability of glomerulonephritis. Differential diagnosis was uraemic encephalopathy and seizure disorder. However, finally it was diagnosed as a case of CNS Lupus - a rare presentation of Systemic Lupus Erythematosus (SLE).
\end{abstract}

Key words: Convulsion, glomerulonephritis, encephalitis, lupus.

J Dhaka Med Coll. 2011; 20(1) : 82-85.

\section{Introduction:}

Involvement of Central nervous system (CNS) may become a severe complication of several autoimmune disorders. Patients can present with either focal symptoms, consisting of stroke and/or transient ischemic attacks, or with central nonfocal symptoms of cognitive dysfunction, acute confusional state, seizures, or psychosis. Neuropsychiatric systemic lupus erythematosus (NPSLE) is likely initiated by inflammatory, thrombotic, and/or cardioembolic etiologies and further exacerbated by antibody, cytokine, and cytotoxin mediators ${ }^{1,2}$. There are no specific laboratory or magnetic resonance imaging (MRI) findings, making a proper diagnosis often difficult. MRI may be negative despite overt neuropsychiatric symptoms. ${ }^{3,4}$ Cerebrospinal fluid (CSF) analyses may show mild lymphocytic pleocytosis, raised protein levels, and IgG indices as well as oligoclonal bands in $25-50 \%$ of cases. ${ }^{5,6}$ In up to $81 \%$ of the cases CNS lupus may occur without systemic SLE activity, ${ }^{7}$ often leading to a delayed diagnosis.

\section{Case Report:}

A 18 years old unmarried female student was admitted into Medicine department of Dhaka Medical College Hospital $(\mathrm{DMCH})$ on $1^{\text {st }}$
February, 2011 with repeated convulsions for 1 day. According to the statement of patient's attendant, she was reasonably well 1 day back. Then she developed convulsion while she was doing household works which was generalized, associated with tongue bite, upward rotation of both eye balls and frothy secretion from mouth. It persisted for 10 to 12 minutes and followed by incoherent talk. The same type of event occurred 5 to 6 times and the patient became unconscious. She was brought to hospital on that night and got admitted through emergency department. There was no history of cough, vomiting, significant weight loss, anorexia, blurring of vision, head injury, travel history to malarial zone, contact with TB patient. On further enquiry, the patient's mother told that she was suffering from episodic headache for last 6-7 months which was not associated with vertigo, vomiting, aura and subsided after taking analgesic medications. She was also suffering from generalized weakness for the same duration for which she did consult with a local doctor and was advised to transfuse blood. She was transfused 2 unit of fresh whole human blood on $30^{\text {th }}$ and $31^{\text {st }}$ January, 2011. On the following day she developed convulsion. The patient's mother also told that around 7

1. Prof. Khan Abul Kalam Azad, Professor of Medicine, Dhaka Medical College, Dhaka.

2. Dr. Md. Hafiz Sardar, Assistant Professorof Medicine, Dhaka Medical College, Dhaka.

3. Dr. Al Mahmood Appolo, Assistant Registrar, Dhaka Medical College Hospital, Dhaka.

4. Dr. Md. Uzzwal Mallik, Indoor Medical Officer, Dhaka Medical College Hospital, Dhaka.

5. Dr. Mallika Sarker, Honorary Medical Officer, Dhaka Medical College Hospital, Dhaka.

Correspondence: Prof. Khan Abul Kalam Azad, Professor of Medicine, Dhaka Medical College, Dhaka. Cell Phone: +8801711890508, Email: markazad24@yahoo.com 
days back patient suffered from low grade fever associated with malaise, mild runny nose. The highest temperature was not recorded. Her bowel and bladder habit were normal. Earlier she was diagnosed as a case of glomerulonephritis and was on steroid for last 2 months. She received Prednisolone $40 \mathrm{mg}$ once with oral iron. She was a nonsmoker, non alcoholic. She was the second issue of her parents. She had two sisters and one brother. All her parents and sibling were apparently healthy. Her father was a farmer and mother was a housewife. They lived in a well built house. She was not allergic to any kind of known allergen. She was properly immunized as per EPI schedule. On examination, the patient was found unconscious, mildly anaemic, having pulse 88 beats /minute, blood pressure was $130 / 80 \mathrm{~mm} \mathrm{Hg}$, normal temperature, respiratory rate 24 breaths/ minute, Glasgow Coma Scale scoring was 3. Tongue bite mark was present, Pupil bilaterally normal and reacting to light and normal fundoscopy, Other cranial nerves could not be examined. Other neurological examination findings were normal and examination of other systems also reveal no other abnormalities. Haematological Investigation showed haemoglobin conc. $12 \mathrm{gm} / \mathrm{dl}$, TC: $12,000 / \mathrm{mm}^{3}$ DC: Neutrophil $=70 \%$, Lymphocytes $=20 \%$, ESR $60 \mathrm{~mm}$ in $1^{\text {st }}$ hour, platelet count $3,00,000 /$ $\mathrm{mm}^{3}$, perip[heral blood film showed normocytic normochromic anaemia, film for malarial parasite : not found, ICT for malaria : negative , Chest X ray PA view : normal, Random blood sugar : $6.2 \mathrm{mg} / \mathrm{dl}$, Seum creatinine : $0.88 \mathrm{mg} /$ dl, Serum electrolytes- Na : $133 \mathrm{mmol} / \mathrm{L}, \mathrm{K}$ : $3.61 \mathrm{mmol} / \mathrm{L}, \mathrm{Cl}: 97 \mathrm{mmol} / \mathrm{L}$, carbon dioxide : $23 \mathrm{mmol} / \mathrm{L}$, Serum calcium : $8.10 \mathrm{mg} / \mathrm{dl}$ ( 8.1 10.4), Serum magnesium: $1.70 \mathrm{mg} / \mathrm{dl}$ (1.6-2.3), Urine R/M/E : appearance : hazy, albumin : +++ , sugar : green yellow, pus cells : 15-80 / HPF, RBC :3-5 / HPF, epithelial cells : 2-4 / HPF. CT scan of the brain revealed diffuse ill defined hypodensity noted in the both occipital region and right parietal and frontal region involving mainly the deep white matter; which is suggestive of posterior reversible encephalopathy syndrome (PRES). CSF analysis was done and found total leucocytes:02, polymorph:0, lymphocytes:100\%, RBC:190/ $\mathrm{mm}^{3}$, Biochemical : protein: $150 \mathrm{mg} / \mathrm{dl}$, glucose: $156 \mathrm{mg} / \mathrm{dl}$, Gram's and AFB staining : no organism found. On this scenario initially it was diagnosed as a case of viral encephalitis with a background probability of glomerulonephritis. Differenial diagnosis was uraemic encephalopathy, seizure disorder. The patient was empirically treated with iv ceftriaxone, iv acyclovir, iv dexamethasone 6 hourly and oral phenytoin.

The patient gained her consciousness on the fifth day of her hospital stay. After gaining the consciousness, patient complained of mild headache. Otherwise she was ambulatory, fully oriented and did not have any neurological deficit. She did not experience any further convulsive episode. As she could talk to us with full orientation we took the opportunity to take a detailed history from the patient. She informed that she was suffering from multiple joint pain for last 1 and a half year and repeated oral ulceration for last 3 months. Joint pain was symmetrical involving small and large joints of both upper and lower limbs and associated with swelling but no redness. Pain persisted for 10 to 12 days and then subsided spontaneously on most occasions. Sometimes patient took some homeopathic medication for the pain. Her daily activities were not grossly impaired due to this pain. She told that she experienced this kind of pain more than 50 times during this period with an irregular interval. But after the month of November, this joint pain was associated with scanty micturition and facial swelling. There was no history of fever, burning sensation of micturition, passage of blood through urine, leg oedema at that time. For these complaints she went to consult a local doctor and was diagnosed as glomerulonephritis and steroid was prescribed. She also complained of repeated oral ulcer for last 3 month which was painful involving buccal mucosa, tongue and palate.There was no history of rash in the face, photosensitivity or abnormal hair loss. On subsequent examinaations, patient was mildly anaemic. Malar rash appeared with typical butterfly pattern sparing the nasolabial folds on 19.02.11, 18 days after admission. Rash was 
also present on her forehead and anterior aspects of both legs. Rash was erythematous and scaly in nature. Oral ulcer was present bilaterally over the hard palate. No other positive findings were found in favor of SLE on examination of musculoskeletal and other systems. Further investigations revealed Urinary total protein: $1.9 \mathrm{gm} / 24$ hours (reference value : upto 0.15 ), Urine volume : $2000 \mathrm{ml} / 24$ hours, Creatinine clearance rate: $130.31 \mathrm{ml} / \mathrm{min}$, Ultrsonography of the whole of the abdomen suggested chronic renal parenchymal disease, ELISA test for ANA : 45 $\mathrm{IU} / \mathrm{ml}$ ( moderately positive), ELISA test for Anti ds DNA : $406.6 \mathrm{IU} / \mathrm{ml}$ ( moderately positive), Complement 3 level : 0.56 gm/L, Complement 4 level : $0.09 \mathrm{gm} / \mathrm{L}$, Complete blood count: haemoglobin conc. $11 \mathrm{gm} / \mathrm{dl}$, TC: $3,500 / \mathrm{mm}^{3}$, DC: $\mathrm{N}=65 \%, \mathrm{~L}=30 \%$, ESR $70 \mathrm{~mm}$ in $1^{\text {st }}$ hour, platelet count: $3,10,000 / \mathrm{mm}^{3}$, PBF: normocytic normochromic anaemia with mild leucopenia, Renal biopsy revealed focal subendothelial deposition of IgG and IgA which was suggestive of stage 3 lupus nephritis.

Considering the history, clinical findings, and investigations the patient was finally diagnosed as a case of Systemic lupus erythematosus with lupus nephritis (stage 3 ) and CNS lupus.

\section{Discussion:}

The main symptoms of CNS lupus can be diffuse (generalized seizures, psychosis) or focal (stroke, peripheral neuropathies). Neuropsychiatric symptoms often occur in the first year of SLE, but are rarely the presenting symptoms of the disease. In studies on the pathology of CNS lupus, vasculopathy, infarcts and haemorrhages are often observed, whereas vasculitis is rare. Endocardial lesions and mural thrombi have also been reported in 33$50 \%$ of CNS lupus patients. ${ }^{8}$-We reviewed the current literature to assess whether there is any specific sign to differentiate between CNS involvement of systemic rheumatic diseases and CNS infection. The clinical distinction is always vague and remains difficult in certain patients because of overlapping clinical features. Differential diagnosis includes toxic leucoencephalopathy caused by therapeutic agents (for example, cyclosporin, tacrolimus, amphotericin B, antineoplastic therapeutic drugs), ${ }^{9}$ hypertensive encephalopathy, and metabolic complication involving the nervous system, such as hydroelectrolytic changes. The clinical presentation does not allow discernment between primary angiitis of the CNS, secondary CNS involvement of rheumatic diseases, and CNS infection, because the signs and symptoms are non-specific. Also, MRI and laboratory findings, including CSF analysis are rarely specific. Only a combination of several diagnostic procedures, additional specific serological tests, and, if possible, stereotactic brain biopsy may ensure a firm diagnosis.

\section{Management:}

CNS vasculitis usually requires hospitalization and high doses of corticosteroids. Infection should be ruled out before treatment is initiated. Treatment of nervous system lupus depends upon its source. Treatment may include: steroids (prednisolone), immunosuppressants (iv cyclophosphamide, monthly), antibiotics, anti-convulsants, antidepressants and counseling. Response to treatment may be dramatic, or gradual improvement may occur over several months. For many people with lupus, nervous system involvement is completely reversible.

\section{Conclusion:}

CNS disease is generally associated with a poor prognosis that is only second in severity to renal involvement. Although studies vary, the consensus of opinion suggests that about $50 \%$ of SLE patients will have neuropsychiatric phenomena at some time during their illness. However, presentation with neurologic features at the onset of the disease is regarded as rare, ${ }^{10}$ occurring only in approximately $3 \%$.

\section{References:}

1. Roldan CA, Shively BK, Crawford MH. An echocardiographic study of valvular heart disease associated with systemic lupus erythematosus. N Engl J Med 1996; 335(19): 1424-30.

2. Johnson RT, Richardson EP. The neurological manifestations of systemic lupus erythematosus. Medicine (Baltimore) 1968, 47(4): 337-69.

3. Weiner SM, Otte A, Schumacher M, Klein R, Gutfleisch J, Brink I, et al. Diagnosis and monitoring of central nervous system involvement 
in systemic lupus erythematosus: value of F-18 fluorodeoxyglucose PET. Ann Rheum Dis 2000; 59: $377-85$.

4. Sibbitt WL Jr, Sibbitt RR, Brooks WM. Neuroimaging in neuropsychiatric systemic lupus erythematosus. Arthritis Rheum 1999; 42: 202638 .

5. Abel T, Gladman DD, Urowitz MB. Neuropsychiatric lupus. J Rheumatol 1980; 7 : 325-33.

6. Christenson RH, Behlmer P, Howard JF Jr, Winfield JB, Silverman LM. Interpretation of cerebrospinal fluid protein assays in various neurologic diseases. Clin Chem 1983; 29: 1028-30.

7. Sibley JT, Olszynski WP, Decoteau WE, Sundaram MB. The incidence and prognosis of central nervous system disease in systemic lupus erythematosus. J Rheumatol 1992; 19: 47-52.

8. van Dam AP. Diagnosis and pathogenesis of CNS lupus. Rheumatol Int 1991; 11(1): 1-11.

9. Illey CM, Kleinschmidt-DeMasters BK. Toxic leukoencephalopathy. N Engl J Med 2001; 345: 425-32.

10. CNS lupus: a study of 41 patients. Neurology 2007; 69(7): 644-54. 